\title{
Magias de cozinha: escravas e feitiços em Portugal - Séculos XVII e XVIII*
}

\author{
Daniela Buono Calainho**
}

\begin{abstract}
Resumo
Este trabalho tem por objetivo apresentar algumas considerações acerca das manifestações mágico-religiosas da população feminina de origem africana em Portugal entre os séculos XVII e XVIII, relacionadas ao uso de ervas, alimentos e outros ingredientes que compunham os feitiços.
\end{abstract}

Palavras-chave: Feitiçaria, Ervas, Africanos.

" Recebido para publicação em 16 de julho de 2012, aceito em 05 de agosto de 2012.

** Professora Assistente do Departamento de Ciências Humanas e coordenadora do Programa de Pós-Graduação em História da Faculdade de Formação de Professores da Universidade do Estado do Rio de Janeiro. calainho@globo.com

cadernos pagu (39), julho-dezembro de 2012:159-176. 
Magias de cozinha

Kitchen Spells: Female Slaves and Magic Spells in Portugal $-17^{\text {th }}$ and $18^{\text {th }}$ Centuries

\begin{abstract}
With this work I intend to present some considerations on the religious-magical practices of African female populations in Portugal during the 17th and 18th centuries, related to the use of herbs, food and other ingredients which were used in magic spells.
\end{abstract}

Key Words: Witchcraft, Herbs, Africans. 
Este trabalho tem por objetivo apresentar algumas considerações acerca das manifestações mágico-religiosas da população feminina de origem africana em Portugal entre os séculos XVII e XVIII, relacionadas ao uso de ervas, alimentos e outros ingredientes que compunham os denominados feitiços. Os africanos e seus descendentes, fossem escravos ou libertos, trouxeram da África variados rituais e costumes, que foram por vezes considerados heréticos pela Igreja católica, condenados pelo tribunal da Inquisição portuguesa como práticas de pacto demoníaco, e, portanto, considerados como feitiçarias. Nesse rol de manifestações, encontramos práticas curativas, adorações de ídolos individualmente ou em grupo, uso de amuletos protetores, dentre outros, mesclados em alguns casos a elementos do cristianismo e da própria cultura europeia, demonstrando um importante mecanismo de reconstrução de uma nova identidade social e cultural fora da África. Procuraremos abordar aqui de que modo o uso de alimentos e outros insumos integraram uma série de feitiços perpetrados pelas mulheres desse grupo população, $e$ a documentação utilizada compõe-se dos processos inquisitoriais a que essas rés foram submetidas.

\section{Curandeiras}

Época de precárias condições sanitárias e de poucos cuidados com a higiene corporal, o bem estar físico e a manutenção da saúde eram difíceis, ameaçados ainda, a todo momento, por fomes, epidemias, guerras ou eventuais calamidades naturais (Mattoso, 1997:200-205). Por outro lado, o conhecimento médico e científico em Portugal, se comparado ao restante da Europa, se restringia a discussões acadêmicas, além de cativo da religião em numerosos aspectos, não resultando, pois, numa prática clínica sistemática que se disseminasse socialmente $e$ que abrangesse desse modo as camadas menos favorecidas. A maioria da população, assim, apelava aos curandeiros que, com seu saber empírico, supriam a carência de um atendimento 
médico eficaz. Acreditava-se que o corpo físico estava sujeito às supostas manifestações de forças sobrenaturais, traduzidas por feitiços variados, sortilégios, espíritos malignos e diabólicos. A doença era vista também como fruto da ação divina, que punia a má conduta humana diante de suas obrigações em face de Deus, estando o corpo completamente vulnerável a essa relação. ${ }^{1}$

A invasão dos corpos por doenças naturais ou sobrenaturais foi campo para os vários curandeiras e curandeiros que proliferaram em Portugal entre os séculos XVI e XVIII, também chamados de "saludadores", "benzedores", ou então "mezinheiros" (Paiva, 1998:104). Numa época em que o limite entre a saúde e a doença era muito tênue, a cura do corpo também impunha o apelo a indivíduos que acreditavam manipular o sobrenatural de diversas maneiras. O trabalho de José Pedro Paiva (1998) sobre a bruxaria em Portugal entre 1600 e 1774 aponta que, em relação às práticas mágicas de um modo geral, $36 \%$ dos réus processados pela Inquisição portuguesa pertenciam a essa categoria; $29 \%$ eram de feitiços para o mal e para influenciar vontades; $29 \%$ eram curandeiros/feiticeiros; $8 \%$ de portadores de bolsas de mandinga e $5 \%$ por fazerem pacto com o Diabo (id.ib.:208).

Laura de Mello e Souza, em seu trabalho sobre a feitiçaria e religiosidade popular no Brasil colônia, considerou os africanos, junto com os indígenas e mestiços, os grandes curandeiros do Brasil colonial, hábeis manipuladores das misturas de ervas $e$ plantas associadas a ritos e cultos inerentes às suas origens, aliados ainda "ao acervo europeu da cultura popular" (Souza, 1986:166). Em Portugal, também os negros atuaram nesse sentido, utilizandose de defumadouros, fervedouros, lavatórios e orações, fosse para

1 "Subjacente a esta sensibilidade, o corpo é concebido como um microcosmos diretamente ligado ao universo visível e invisível, o que explica a fluidez de fronteiras entre o corpo e o meio que o rodeia, numa palavra, a vulnerabilidade essencial. Daí a necessidade de negociar e manter, sob vigilância permanente, um frágil e delicado equilibrio entre o corpo e o mundo exterior" (Bethencourt, 1987:52). 
restituir a saúde, fosse para curar de feitiços - muitas vezes doenças completamente desconhecidas, cujos sintomas assumiam um caráter sobrenatural. Dentre as motivações que levaram negros e mulatos a serem denunciados e processados pelo Santo Ofício, o curandeirismo aparece num percentual de 29\%, conforme mostra a tabela abaixo. Acompanhando o movimento geral da feitiçaria no Reino, 48,2\% eram de mulheres curandeiras.

Sexo dos negros e mulatos processados e denunciados por feitiçaria pela inquisição portuguesa (séculos XVI a XVIII)

\begin{tabular}{|l|c|c|c|c|c|c|c|c|}
\hline & \multicolumn{2}{|c|}{$\begin{array}{c}\text { Relacionamentos } \\
\text { pessoais }\end{array}$} & \multicolumn{2}{l|}{ Curandeirismo } & \multicolumn{2}{c|}{ Proteção } & \multicolumn{2}{|c|}{ Totais } \\
\hline & $\#$ & $\%$ & $\#$ & $\%$ & $\#$ & $\%$ & $\#$ & $\%$ \\
\hline Homens & 11 & 30.5 & 14 & 51.8 & 30 & 100 & 55 & 59.1 \\
\hline Mulheres & 25 & 69.5 & 13 & 48.2 & 0 & 0 & 38 & 40.9 \\
\hline Totais & 36 & 100 & 27 & 100 & 30 & 100 & 93 & 100 \\
\hline
\end{tabular}

Fontes: ANTT, Processos inquisitoriais, Cadernos do Promotor e Livros de denúncias referentes aos Tribunais de Coimbra, Évora e Lisboa, séculos XVI a XVIII.

Associadas às virtudes das ervas - ou mesmo isoladamente, outras substâncias de origem animal ou vegetal eram largamente utilizadas, tanto para lavar os enfermos como para serem postas como emplastros nos ferimentos ou partes doloridas. $E$ foi nas cozinhas que muitos desses procedimentos curativos começaram. Vários curandeiros negros também utilizavam à farta elementos ligados ao culto cristão, como água benta, orações, hóstias, terços, cruzes, devoções a santos, dentre outras, no sentido de potencializar os efeitos das curas, revelando um evidente sincretismo mágico-religioso. Vejamos alguns exemplos.

A forra Inez do Carmo, em 1754, confessou em seu processo inquisitorial que conseguiu curar uma mulher, em Tavira, acometida por intensas dores de cabeça, "sem que lhe abrandassem os remédios que o médico lhe aplicara". A receita compunha-se de um cozimento de vinho morno, alecrim e "uns pós que ela tirava do seio embrulhado em um papel". Em outra 
ocasião, também encontrou uma mulher com dores na perna direita, "e que os médicos chamavam de dor artérica, a qual não tinha obedecido aos remédios da medicina', e aplicou-lhe um emplastro de óleo de arruda, com algumas ervas e dois ovos, seguindo-se a isso orações no adro da igreja com velas acesas". ${ }^{2}$

As explicações sobrenaturais, ancoradas num profundo sentimento místico e religioso, tomavam o lugar do pouco conhecimento científico em relação às doenças e seus sintomas, ao funcionamento do corpo e aos possíveis remédios. Assim, as moléstias inexplicáveis eram vistas como feitiços - sobretudo as de caráter psíquico ou neurológico - e tratadas como tal, distinguindo-se então os curandeiros que curavam de doenças ou malefícios, daqueles que os promoviam. Em alguns casos, os próprios médicos sugeriam a hipótese de o doente estar enfeitiçado, assumindo sua inaptidão para curar.

Frangos e a galinhas foram animais bastante usados pelas escravas $e$ forras para variados objetivos, costume tradicionalmente estabelecido em praticamente toda a África negra (Chevalier e Gheerbrant, 1998:457). A já citada forra Inês do Carmo confessou que curou uma pessoa enfeitiçada fazendo-a beber $e$ depois vomitar um cozimento de vinho branco, uma galinha preta, ervas e um pedaço de camisa do doente. ${ }^{3}$ Essa ré também fazia vários unguentos com sangue de galinha, largamente utilizado na confecção de beberagens e emplastros.

Entre os povos bantu, e entre a maioria dos povos africanos, as forças vitais, que perpetuavam a vida e proporcionavam energia, eram da maior importância, concentrando-se em pontos fundamentais do corpo como cérebro, sangue, coração, fígado, mas também em unhas e cabelos, que representavam emanações do espírito, daí a crença na sua energia (Deschamps, 1962:11). Veículo da vida, fluido vital, o sangue, especialmente, era instrumento de toda sorte de feitiços, procedimentos terapêuticos e

\footnotetext{
2 ANTT, Inquisição de Évora, Processo 5940.

3 idem.
} 
contratuais, fundamental também para selar o pacto demoníaco na percepção dos demonólogos europeus (Bethencourt, 1987:115).

Os negros do Reino deixaram alguns traços de cerimônias ou ritos próprios das culturas de origem africana, sempre difíceis de identificar com alguma precisão etnográfica, em maior ou menor grau assimilados ao catolicismo. A comunicação com as almas, o culto aos mortos, era prática corrente também entre muitos povos africanos, sendo utilizados ainda como forma de identificação de feitiços e a busca da sua respectiva cura. Os espíritos eram tratados e alimentados, ou então eram incorporados pelo curandeiro. O transe acontecia sobretudo quando se supunha estar o enfermo "assombrado" ou "possuído" por algum defunto ou espírito maligno, que era denunciado ao mesmo tempo em que se dizia o que fazer para livrar-se da possessão ou enfermidade. De acordo com as crenças dessas sociedades, a vinculação dos vivos aos seus antepassados se fazia através de oferendas e sacrifícios (Paiva, 1998:106). A compreensão da prática do culto aos mortos pelos africanos em Portugal remete-nos também a aspectos interessantes da religiosidade de alguns grupos étnicos específicos, particularmente dos bantu (Slenes, 1995:7). Na cosmogonia deste grupo, o mundo se dividia no plano dos vivos e dos mortos, sendo a relação entre ambos intermediada por ritos realizados por líderes religiosos que detinham o conhecimento mágico para tal (MacGaffey, 1986:199). Os mortos, que nesse imaginário possuíam a cor branca, recebendo homenagens e oferendas, influenciavam os vivos, por vezes dando-lhes poder, o que derivava do contato que se estabelecia entre esses dois mundos (MacGaffey, 1986:43).

A prática de "pôr a mesa às almas" - termo corrente nos processos inquisitoriais - normalmente em caminhos ou encruzilhadas, alimentando-as com pão, bolos, queijo, mel, água e vinho, além de obter curas, dava conta do paradeiro de objetos perdidos, paradeiro de pessoas vivas e até de pessoas já mortas. "Este negro faz curas e evoca anjos e almas dos defuntos, e também as almas dos que ainda estão vivos", denunciou Custódio 
Vicente, em 1737, a Sebastião Barbosa, que curava oferecendo ovos e doces aos espíritos. ${ }^{4}$

A escrava congolesa Maria Crioula foi denunciada à Inquisição de Lisboa, em 1790, por ser "poderosa feiticeira" e andar com vários negros adivinhadores. Segundo apurações do Comissário do Santo Ofício, um deles dizia que era escravo da alma de um Capitão, para quem ela fazia pão de ló, e o ajudava nas curas que fazia. ${ }^{5}$

A prática de oferendas em muitas regiões da África - Costa da Guiné, por exemplo -, como alimentos, sangue de animais sacrificados e bebidas (aguardente ou vinho), foi comum nas cerimônias de evocação de deuses ou espíritos antepassados. Os objetivos dos ritos determinavam as características dos animais imolados (vacas, porcos, cabras e aves), como a coloração e o tipo da pelagem (Carreira, 1961:530).

As encruzilhadas tinham um significado privilegiado nas práticas mágicas. Local de convergência de caminhos, de passagem, espaço preferido de contato com os espíritos e onde o homem procurava se desvencilhar de forças negativas, lugar onde também se erigiam altares, capelas, inscrições, cruzeiros, em muitos povos exerceu forte influência. Vista como espaço sagrado em contraposição ao profano, a encruzilhada pode ser pensada também como o limiar de que fala Mircea Eliade, o ponto de comunicação com o mundo sagrado ou, simplesmente, lugar de passagem (Eliade, 1992:35-39).

Para várias comunidades na África Central, Guiné e Nigéria, as encruzilhadas tinham um caráter divino, onde rituais de fecundidade e sacrifícios de animais eram realizados. Oferendas como os primeiros frutos das colheitas, utensílios domésticos, aves, ossos de animais sacrificados, ovos, dentre outros, eram postas pelos bambarras do Mali, por exemplo, para os espíritos que intervinham em seu cotidiano, principalmente na época da

4 ANTT, Inquisição de Lisboa, Cadernos do Promotor s/n, livro 324.

5 ANTT, Inquisição de Lisboa, Processo 14975. 
semeadura. Ao mesmo tempo também nas encruzilhadas se abandonavam elementos nocivos e impuros, como dejetos $e$ crianças mortas, na crença de que os espíritos aí circulantes transmutariam essas forças em energias positivas para os homens. A terra oriunda da encruzilhada servia ainda de ingrediente para numerosos fins (Chevalier e Gheerbrant, 1998:367-370).

Todas essas tradições foram transmigradas com os negros no processo de escravização que sofreram a partir de meados do século XV, associando-se a elementos do cristianismo e, evidentemente, assumindo especificidades em função da região de onde vieram e de onde foram se assentar. Os negros em Portugal frequentaram à farta as encruzilhadas. A já citada Inês do Carmo, por exemplo, curou uma criança levando-a numa encruzilhada onde estendeu um pano no chão com fatias de pão depois de passadas por cima da menina doente, proferindo depois algumas palavras. ${ }^{6}$

Adorações de imagens, individualmente ou em grupo, e manifestações envolvendo danças e batuques puderam ser encontradas entre as africanas do Reino com o intuito de realizarem curas e adivinhações. Natural e moradora da povoação de Cachéu, Costa da Guiné, Chrespina Peres, de 1668, foi ré num processo que demonstra algumas relações interessantes com as práticas de feitiçaria em Portugal. Em companhia de "negros gentios", fazia "chinas", que segundo consta em seu processo, eram "umas idolatrias que toda a gente vinda de Guiné adora". De acordo com testemunhos, as chinas eram ídolos dos "gentios da terra" (isto é, os africanos não cristianizados), objetos de devoção dos negros e ainda dos brancos que habitavam a região. ${ }^{7}$ Ajoelhados, sacrificavam galinhas, galos, vacas, bois, cabras $e$ punham o sangue misturado a vinho dentro de uma panela

\footnotetext{
6 ANTT, Inquisição de Évora, Processo 5940.

7 ANTT, Inquisição de Lisboa, Processo 2079. Do Senegal à Serra Leoa, a designação de china englobava ao mesmo tempo os locais de cerimônias e os ídolos desses grupos. Ver Carreira (1961:54).
} 
pendurada na parede, realizando a cerimônia em função dos desejos e necessidades: coisas perdidas, matrimônios desejados, curas de doenças. ${ }^{8}$ A carne dos animais, dizia Sebastião Vaz, contramestre de um navio e testemunha do caso, "comem-na, e tem muita fé nestes abusos". Entre os povos da Costa da Guiné, do mesmo modo que a força vital do sangue dos bichos imolados ia para os deuses, a ingestão da carne pelos fiéis representava a transmissão dessa energia para eles (Deschamp, 1962:43). Disse ainda que havia um lugar chamado Vila Quente, onde se reuniam "gentios" com cristãos e que lá "há muitos negros cristãos e forras que ali dentro de suas casas como fora da povoação fazem os mesmos ritos em companhia dos gentios". Chrespina Peres lutava pela saúde da filha, e numa noite levaram-na "para as choupanas dos seus negros cativos, donde dizem a lavaram e usaram com ela de cerimônias gentílicas". Foi também denunciada por realizar o rito em pleno navio onde ia viajar seu marido, que fazia resgate de negros no rio Bujago: "mandou um negro degolar uma vaca e pôs o sangue com vinho de palma e farinha de milho na bomba do navio para que fossem bem e trouxesse muitas riquezas". Essa prática era comum em Cachéu, segundo o testemunho do piloto Diogo Gaspar, pois quando lá descia traziam animais para sacrificarem.

Eram muitos aqueles que solicitavam os serviços das feiticeiras e feiticeiros portugueses, de um modo geral pessoas de baixa condição social, categoria à qual também pertenciam. ${ }^{9}$

8 O Pe. Fernão Guerreiro, em 1604, deparou-se com essa prática, descrevendoa assim: "Tomam muitos paus, cada um de palmo e meio, todos muito pretos em razão da variedade dos licores que lançam em umas vasilhas, que é sangue de diversos animais com que tingem estes paus; $e$ as vasilhas são umas panelinhas juntas umas das outras, entressachadas com pontas de cabras; destes paus fazem um feixe, que fica parecendo um cepo de talhar carne, de altura de um palmo $e$ meio, do qual estão dependuradas por umas cordinhas delgadas duas ou três caveiras de cachorros. E eis aqui o deus que esta cega e brutal gentilidade adora e mete no coração e isto é o que chamam China" (Brásio,1953:204).

9 José Pedro Paiva (1998:173) menciona um tal Luís de la Penha, que teve seu caderninho de clientes, contendo cerca de 400 nomes, apreendido pela Inquisição. 
Apesar disso, clérigos, nobres e até médicos os procuravam, em geral por não terem conseguido sucesso na medicina da época $e$ na Igreja. Foi o caso, por exemplo, do Dr. Francisco Dias, ironicamente Familiar e médico do Santo Ofício, que curou-se graças a uma feiticeira mais adiante denunciada por ele em carta escrita ao Tribunal de Coimbra. Criado "com o leite da igreja", não via desculpa em seu erro por ter se curado com "pessoas supersticiosas e feiticeiras", obrigado que foi "pelo amor da vida com receio da morte" (Paiva, 1998:174).

Mas evidentemente que os próprios negros apelavam para os seus iguais. Muitos segredos ainda quanto à mistura de ervas $e$ ingredientes provavelmente eram restritos a eles, atuando os curandeiros africanos em sua própria comunidade, não tendo muitas alternativas nesse sentido e contando mesmo com seus companheiros de origem na tentativa de minorarem sua condição.

\section{Feitiços amorosos}

As manifestações mágico-religiosas tidas por feitiçarias vinculadas aos relacionamentos pessoais, amorosos ou de inimizades e ódios foram inúmeras, exaustivamente exploradas e estudadas pelos historiadores da bruxaria portuguesa, colonial $e$ europeia em geral. Contidas também na documentação produzida pelo Santo Ofício, tais manifestações são narradas com riqueza de detalhes nos processos inquisitoriais. Comportamentos relativos aos amores, desejos sexuais, desafetos, ódios e angústias traduziram-se num sem número de procedimentos e práticas mágicas no sentido de induzirem vontades, perpetrarem adivinhações e provocarem malefícios, tanto por brancos como negros. Diria Gilberto Freyre que

o amor foi grande motivo em torno do qual girou a bruxaria em Portugal. Compreende-se aliás a voga dos feiticeiros, das bruxas, das benzedeiras, dos especialistas em sortilégios afrodisíacos, no Portugal desfalcado de gente que, num extraordinário esforço de virilidade, pôde ainda 
colonizar o Brasil. A bruxaria foi um dos estímulos que concorreram, a seu modo, para a superexcitação sexual de que resultou preencherem-se legítima ou ilegitimamente, na escassa população portuguesa, os claros enormes abertos pelas guerras e pelas pestes (Freyre, 1958:450-451).

As estatísticas nos revelam que para Portugal, nos séculos XVII e XVIII, as práticas mágico-religiosas voltadas para as relações afetivas aparecem genericamente como uma das mais comuns, $e$ para os negros e mulatos chegam a um percentual de $38,7 \%$ entre os séculos XVI e XVIII. O excedente feminino $e$ as crescentes limitações de uniões informais em prol do sacramento do matrimônio, estimulado pelo espírito tridentino, cristalizaram as tensões entre as mulheres e homens (Bethencourt, 1987:75).

$\mathrm{O}$ universo das relações pessoais, de "inclinação de vontades", era fundamentalmente feminino também entre os negros, correspondendo a $69,5 \%$ dos casos. Induzir os homens ao matrimônio, ao intercurso sexual, a prendê-los para sempre aos seus encantos, era comum entre as negras, tendo estas ainda inúmeras "clientes" brancas. As feiticeiras de Angola - as "gangazambes", "atraíam ódio e amor, e nisto entram muitos brancos da terra" através de variada gama de procedimentos $e$ ingredientes. ${ }^{10}$ Citemos agora alguns exemplos interessantes.

A forra Catharina da Maya foi degredada para Angola pelos inquisidores de Lisboa, em 1658, pela eficiência de suas receitas no arranjo de casamentos, por vezes associadas a elementos cristãos, como orações que evocavam santos. Uma dessas receitas se compunha de sangue de criança, sal bento de batismo, três velas verdes, pó vermelho lançado numa igreja, um coração de um galo atravessado com alfinetes e um dente de cachorro. "Quando este cão ladrar, e quando este galo cantar, então há de unir fulano comigo falar", era o que ela proferia para dar mais

${ }^{10}$ ANTT, Conselho Geral do Santo Ofício, Coleção Manuel da Cunha, Tomo XXXI, livro 272. 
eficácia à receita, seguido de um credo a São Mateus por cada alfinete tirado. ${ }^{11}$

A parda Maria Ortega, residente em Lisboa, ensinava, em 1637, "desconjuros de palavras" para unir homens e mulheres, gabando-se de ter "grande mão" para essas tarefas. Furava o coração de um frango vivo, fervendo-o em vinagre; utilizava orações $e$ fervedouros de vinagre e enxofre para adivinhar $o$ paradeiro de pessoas, e apelava ainda para as almas: quase meianoite, arrumava um altar com duas velas acesas, um pão e um copo de vinho embaixo de um painel do Purgatório com a figura de Cristo crucificado. Depois de rezar 18 rosários ao longo de três noites seguidas "pela alma mais necessitada", esta lhe viria falar o que quer que perguntasse ou atender o que pedisse. ${ }^{12}$

Isabel Furtada, que vivia "de portas a dentro" com um homem, finalmente conseguira casar em 1612 graças às artes da escrava Domingas Fernandes, natural da Guiné, que usou "ossos de finado" - artigo valoroso entre as feiticeiras - e um lenço do pretendido, além de pó de pedra d'ara e pó de olhos de cães. Unia homens casados a outras mulheres, tirava amantes de maridos e, para desligar homens, se valia de fervedouros de urina junto a outros ingredientes. ${ }^{13}$ Para esses mesmos fins, também colocava numa encruzilhada à noite fervuras de bode, jogando a seguir uns pós, não identificados no processo, na porta do futuro marido da cliente. ${ }^{14}$

$\mathrm{O}$ uso de animais peçonhentos era comum, sobretudo sapos, que secos e transformados em pó, eram ministrados às

\footnotetext{
${ }^{11}$ ANTT, Inquisição de Lisboa, Processo 11834.

${ }^{12}$ ANTT, Inquisição de Lisboa, Processo 834.

${ }^{13}$ ANTT, Inquisição de Évora, Processo 10101.

${ }^{14}$ Idem. Pós de várias origens eram muito usados para enlaçar pessoas. A famosa feiticeira colonial Maria Gonçalves Cajada, a "Arde-lhe-o-rabo", uma das várias estudadas por Laura de Mello e Souza, fazia pós sob encomenda, como o que saiu "de um sapo tersado e que lhe custaram muito trabalho para fazê-los, e que fora ao mato falar com os diabos e que vinha moída deles". Ver Souza (1986:239).
} 
vítimas. Catarina Maria, de Évora, em 1750, foi denunciada por ter espetado um sapo para assar, e o que dele pingou colocou num pão, dizendo "assaste sapo, e pingaste pão para cegar os olhos deste cabrão", para que seu marido não descobrisse seus pecados. ${ }^{15}$

As secreções humanas, cabelos e unhas aparecem novamente como ingredientes poderosos da magia erótica, usados para alimentar e desfazer relacionamentos. Marcelina Maria, presa em 1734, aprendeu que se tivesse cópula com um homem $e$ quisesse prendê-lo, molhasse o dedo "no vaso natural" $e$ fizesse duas cruzes sobre os olhos; podia também dar-lhe de comer um ovo enfiado entre suas pernas durante uma noite. Aproveitou a ocasião para denunciar que uma tal Catarina Inácia, amante de um criado de seu primeiro senhor, "se trata com uma mulata feiticeira chamada Felícia, e com outras mais, usando de feitiçarias" para que seu marido não descubra seus outros amantes ${ }^{16}$... A forra Ana Josefa, vingando-se do marido, deu-lhe de comer um bolo, incluindo nos ingredientes "cabelos de cabeça, sovaco e das partes pudentas". ${ }^{17}$

A angolana Antônia foi denunciada, em 1733, por atormentar seu amante, que havia deixado de vê-la, com inchações no ventre, dores de estômago, ânsias no coração $e$ dores de cabeça. "Atravessada pelo peito e pelo pescoço, sem poder dormir nem descansar", a esposa também começou a sentir as mesmas coisas, e implorando "pelas chagas de Cristo", contratou Maria de Jesus, afamada feiticeira negra de Lisboa, que desfez o feitiço que atordoava o casal: dentro de um saco de lã, posto embaixo da cama, colocou um boneco atravessado pela cabeça com alfinetes, um embrulho contendo ossos de defunto, "uns pauzinhos" e um pano vermelho. ${ }^{18}$

${ }^{15}$ ANTT, Inquisição de Lisboa, Cadernos do Promotor 108, livro 300.

${ }^{16}$ ANTT, Inquisição de Lisboa, Processo 631.

${ }^{17}$ ANTT, Cadernos do Promotor 118, livro 306.

${ }^{18}$ ANTT, Cadernos do Promotor 99, livro 292. 
É importante chamar atenção sobre o caráter ambíguo da figura da feiticeira. Ao mesmo tempo solicitada para satisfazer os desejos de seus clientes - curas, amores etc. -, era também bastante temida pelas possibilidades perversas inerentes às suas habilidades. A elas imputavam-se desgraças e dissabores: mortes repentinas de adultos ou recém-nascidos; doenças desconhecidas que ainda a medicina estava longe de decifrar; destruição de bens materiais como colheitas, animais, embarcações; impotência sexual; confecção de vodus - bonecos compostos de objetos da vítima (Paiva, 1998:126). Para tudo isso, ervas e alimentos os mais variados eram matéria fundamental desses "feitiços".

\section{Feitiçaria e escravidão}

Mesmo em Portugal, os escravos urdiram toda sorte de magias para se livrarem da ira de seus senhores, embora no Reino o escravismo fosse ancilar ou secundário na economia portuguesa. Mas isso não significa que a resistência $e$ a necessidade de proteção contra a violência senhorial não fizessem parte do cotidiano dos cativos; nesse sentido, a feitiçaria foi uma alternativa a mais para aliviar as tensões entre senhores e escravos. Não foi à toa que de todos os negros, negras, mulatos $e$ mulatas processados e denunciados por feitiçaria $48,4 \%$ fossem escravos $e$ $18,3 \%$ forros.

A resistência ao sistema escravista no mundo colonial se apresentou sob diversas formas, desde formas explícitas - como as fugas individuais e coletivas, revoltas e formação de quilombos até as mais sutis, vinculadas ao quotidiano $e$ vivenciadas no interior do próprio sistema - como roubos, suicídios, abortos, assassinatos e atentados à produção senhorial (Reis e Silva, 1989). As práticas tidas por magia inseriram-se, pois, nessa segunda categoria. Laura de Mello e Souza considerou-as como necessárias à formação social escravista colonial, uma vez que eram ao mesmo tempo alternativa de luta contra o sistema, "muitas vezes a 
única possível", assim como instrumento legitimador da repressão e violência. ${ }^{19}$

Em Portugal, as escravas procuraram se resguardar dos maus tratos que por vezes sofriam, valendo-se de toda sorte de feitiços, tal qual os escravos que serviram no Brasil. Mastigar determinada erva na crença de que ela acalmaria os humores dos senhores, ou ainda utilizar as raspas das solas de seus sapatos como material de feitiços eram costumes também observados nas denúncias e processos, não só em Portugal, mas também no Brasil.

Causar moléstias físicas aos senhores também foi prática corrente, a exemplo de Catarina Maria, angolana, presa em 1732 suspeita de pôr feitiços na comida de seu segundo senhor. Catarina estava convicta de seus quitutes haviam deixado-o com "tormentos no coração", insônias, febres, tosses, dor de dente, de ouvido, incômodo nos olhos, no nariz e estômago. ${ }^{20}$ Adoecer os senhores e provocar-lhes um mal mais direto eram ações que também compunham o leque de manifestações dos escravos e escravas, embora seja importante frisar que a feitiçaria praticada por eles em Portugal - e também no Brasil - não visava uma oposição frontal e direta ao sistema escravista, encetando rebeliões ou mesmo libertação, fosse violentamente, fosse pela via da alforria. Estava em jogo, sobretudo, sua sobrevivência, muito mais do que propriamente uma resistência frontal ao sistema.

Quando queriam ser vendidos, por vezes recorriam a práticas mágico-religiosas. Raspas de sola do sapato, escarro e lixo da casa do senhor, junto com um pouco de enxofre e algumas ervas foi o que pediu José Francisco, em Lisboa, para ajudar uma escrava em 1730. Esses ingredientes, postos numa bolsa enterrada

19 "No Brasil, essa crença no poder redentor e purificador da violência física encontrou poderoso aliado na necessidade escravista do castigo exemplar. Escravos podiam ser legitimamente castigados também porque eram feiticeiros. Enxergá-los como feiticeiros, por sua vez, foi uma das manifestações da paranoia da camada senhorial na colônia" Souza (1986:205).

${ }^{20}$ ANTT, Inquisição de Lisboa, Processo 6286. 
na porta do senhor por três dias, lhe garantiria a venda. ${ }^{21} \mathrm{O}$ Santo Ofício serviu assim, em certos casos, para alguns escravos tentarem se desvencilhar de sua terrível condição. O jesuíta Antonil, em seu Cultura e opulência do Brasil, publicado em inícios do século XVIII, já advertira os senhores de engenho no Brasil para que moderassem os castigos aos escravos, pois do contrário poderiam fugir "para algum mocambo no mato", suicidarem-se ou então vingarem-se de seus algozes enfeitiçandoos através de comidas as mais diversas (Andreoni, 1967:64). A documentação inquisitorial é farta em mostrar que muitos desses escravos e escravas de fato apelaram para seus saberes "mágicos" nas relações com seus senhores.

A difícil condição de sobrevivência das negras escravas $e$ forras era de algum modo compensada com práticas mágicoreligiosas, tidas pelo Tribunal do Santo Ofício como heréticas. Detentoras de saberes "mágicos", a fama pública fazia-as requisitadas também por brancos, o que geralmente elevava seu "status" junto à sua própria comunidade e possibilitava, através das curas, feitiços amorosos e confecção das mandingas, a obtenção de ganhos materiais não só em dinheiro, mas ainda em gêneros. E nesse universo, o uso da comida, de ervas variadas $e$ de outros insumos foi veículo fundamental na confecção dos feitiços, todos eles elaborados a partir de uma receita. Intenções, desejos, sentimentos os mais variados eram direcionados aos alimentos, num universo mágico de crenças que caracterizou uma dimensão do mundo feminino nos Tempos Modernos.

\section{Referências bibliográficas}

ANDREONI, João Antônio. Cultura e opulência do Brasil por suas drogas e minas. São Paulo, Companhia Editora Nacional, 1967.

BETHENCOURT, Francisco. O imaginário da magia. Feiticeiras, saludadores e nigromantes no século XVI. Lisboa, Centro de Estudos de História e Cultura Portuguesa, 1987.

${ }^{21}$ ANTT, Inquisição de Lisboa, Processo 11767. 
Magias de cozinha

BRAGA, Isabel M. R. D. Sabores do Brasil em Portugal. Descobrir e transformar novos alimentos (séculos XVI-XXI). São Paulo, Editora Senac, 2010.

BRÁSIO, Antônio. Monumenta missionária africana. Lisboa, Agência Geral do Ultramar, 1953.

CARREIRA, Antônio. Símbolos, ritualistas e ritualismos ânimo-fetichistas na Guiné Portuguesa. Boletim cultural da Guiné Portuguesa, Separata do n 63 do ano XVI, Bissau, 1961.

Chevalier, Jean e GheERBRAnT, Alain. Dicionário de símbolos. Rio de Janeiro, José Olympio Editora, 1998.

ELIADE, Mircea. O sagrado e o profano. A essência das religiões. Lisboa, Ed. Livros do Brasil, 1992.

FREYRE, Gilberto. Casa-Grande e senzala. Rio de Janeiro, José Olympio, 1958.

H. DesChAmpS, Hubert. Las religiones del Africa negra. Buenos Aires, Editorial Universitaria de Buenos Aires, 1962.

MACGAFFEY, Wyatt. Religion and society in Central África. Chicago, The University of Chicago Press, 1986.

Mattoso, José. História de Portugal. No alvorecer da Modernidade. Lisboa, Estampa, vol.3, 1997.

PAIVA, José Pedro. Bruxaria e superstição num país sem "caça às bruxas”. 1600/1774. Lisboa, Notícias Editorial, 1998.

PRIORE, Mary del. (org.) História das mulheres no Brasil. São Paulo, Contexto, 1997.

REIS, João e SILVA, Eduardo. Conflito e negociação. A resistência negra no Brasil escravista. São Paulo, Companhia das Letras, 1989.

SLENES, Robert. Malungu, Ngoma vem! África encoberta e descoberta no Brasil. Cadernos do Museu da Escravatuta, no 1 , Luanda, Ministério da Cultura, 1995, pp.5-24.

SouZA, Laura de Mello e. O Diabo e a terra de Santa Cruz. Feitiçaria e religiosidade popular no Brasil colonial. São Paulo, Companhia das Letras, 1986. 